www.jmscr.igmpublication.org

Impact Factor 5.84

Index Copernicus Value: 71.58

ISSN (e)-2347-176x ISSN (p) 2455-0450

crossref DOI: _https://dx.doi.org/10.18535/jmscr/v5i9.79

Journal Of Medical Science And Clinical Research

\title{
Effect of Daily versus Supervised Weekly Single Dose Oral Iron in Pregnant Women: Hematological Outcome
}

\author{
Authors \\ Dr Ruchi Saxena ${ }^{1}$, Dr Karanveer Singh Solanki, Dr Madhu Patni (Bhat) ${ }^{3}$ \\ ${ }^{1}$ Associate Professor, Dept. of Obstetrics \& Gynaecology, S.P Medical College, Bikaner, Rajasthan \\ ${ }^{2}$ Resident, Dept of Obstetrics \& Gynaecology, S.P Medical College, Bikaner, Rajasthan \\ ${ }^{3}$ Sr. Professor \& Head, Dept. of Obstetrics \& Gynaecology, S.P Medical College, Bikaner, Rajasthan \\ Corresponding Author \\ Dr Ruchi Saxena \\ Email: drgajendrasaxena@gmail.com, Mobile no.:09414603668
}

\begin{abstract}
Background: Anemia during pregnancy is an important risk factor of morbidity and mortality. Anemia especially if severe is directly or indirectly responsible for $40 \%$ of maternal deaths. Iron supplementation programmes are most practical short term approach to alleviate the problem. The present study aim to compare the effect of daily versus supervised single dose weekly oral iron supplementation, so that compliance is almost 100\%, on haematological parameters in pregnant women.

Material \& Methods: This is a prospective study of 200 women, attending antenatal clinic of department of obstetrics and gynecology, P.B.M. hospital and AG group of hospitals, S.P. medical college, Bikaner (Rajasthan). The women were randomly allocated in to two groups; one receiving daily and other receiving supervised single dose weekly iron supplementation. After taking informed consent, complete history and physical examination, all 200 pregnant women were subjected to routine antenatal investigations. Apart from routine antenatal investigation, detailed haematological work up was also done.

Results: In our study observed that difference of haemoglobin levels at baseline and at time of final sampling is find to be statistically insignificant $(p>0.05)$. When the serum feeitin levels are compare between group $A$ and group $B$, the difference at baseline is find to be statistically insignificant $(p>0.05)$ whereas the difference in serum ferritin levels after 3 months oral iron supplementation is find to be statistically highly significant $(p<0.05)$. In our study showed that haematological indices in group $A$ and group $B$ at the initiation of iron supplementation are comparable to each other. $P$ value are not significant and after 3 month of iron supplementation there is no significance difference in haematological indices except in $\mathrm{MCHC}$.

Conclusion: Our study concluded that weekly supervised iron therapy is cheaper, easy and more compliant $\&$ also has slightly better results than unsupervised daily iron therapy for prophylaxis of anemia.

Keywords: Iron supplementation, Anaemia, Hematological parameters, Pregnant.
\end{abstract}

\section{Introduction}

Iron deficiency anemia is the most common nutrition disorder in the world. ${ }^{1}$ Pregnant women are at special risk of developing anemia because of the extra iron required by fetus, placenta and increased maternal red cell mass in second and 
third trimester. Anemia during pregnancy is an important risk factor of morbidity and mortality. In India, approximately 1.35 lacks women die from pregnancy and child birth related conditions and $20 \%$ of these deaths are contributed by anemia. Its prevalence may be high as $88 \%$ in some parts of India. ${ }^{2}$ Anemia especially if severe is directly or indirectly responsible for $40 \%$ of maternal deaths. $^{3}$

Iron supplementation programmes are most practical short term approach to alleviate the problem. However, routine supplementation programme such as "National Nutritional Anemia Prophylaixs Programme" during the fourth five year plan has not led to much alleviations of the prevalence of iron deficiency anemia in pregnancy in India due to multifactorial reasons. ${ }^{4}$

The main problem of daily iron supplementation is a high incidence of undesirable side effect such as epigastric pain, nausea, vomiting, constipation and diarrhoea leading to poor compliance. Large doses of iron are also associated with reduction in absorption of other elements like zinc. ${ }^{5}$ Studies indicate that administration of daily oral iron impairs the absorption of a subsequent iron dose. ${ }^{6}$ All these factors have motivated a few experimental studies searching for alternative efficacious iron supplementation schemes that will minimize the side effects. i.e. other than routine oral iron.

While comparing daily to weekly IFA supplementation, weekly therapy is undoubtedly superior then daily in terms of reducing side effects as well as cost and improving compliance. ${ }^{7}$ The present study aim to compare the effect of daily versus supervised single dose weekly oral iron supplementation, so that compliance is almost $100 \%$, on haematological parameters in pregnant women.

\section{Material \& Methods}

This is a prospective study of 200 women, attending antenatal clinic of department of obstetrics and gynecology, P.B.M. hospital and AG group of hospitals, S.P. medical college, Bikaner (Rajasthan).

\section{Inclusion criteria}

1. Pregnant women<20 weeks period of gestation registered for antenatal care.

2. No history of prior iron intake.

\section{Exclusion criteria}

1. Hb level $<8.5 \mathrm{gm} / \mathrm{dl}$

2. History of chronic illness past or present pregnancy

3. History of prior blood transfusion

4. Multiple pregnancies

5. Obstetrics haemorrhage in past or present pregnancy

\section{Methods}

After taking informed consent, complete history and physical examination, all 200 pregnant women were subjected to routine antenatal investigations. Apart from routine antenatal investigation, detailed haematological work up was also done.

Two ml venous blood in EDTA vial was taken and complete blood count including Hb., Platelet, $\mathrm{MCV}, \mathrm{MCH}, \mathrm{MCHC}$. Hematocrit was measured by Symax K 1000 analyzer machine. $5 \mathrm{ml}$ venous blood was collected for serum separation and stored for ferritin estimation.

The women were randomly allocated in to two groups; one receiving daily and other receiving supervised single dose weekly iron supplementation. Oral supplementation was started between 14 to 20 weeks period of gestation. Standard Government of India of NFI (large) tablets was used throughout the study. Each tablet contains dried ferrous sulphate IP $335 \mathrm{mg}$ equivalent to $1000 \mathrm{mg}$ of elemental ferrous iron and folic acid $500 \mu \mathrm{g}$.

Women in group A were instructed to choose any day of the week and take supervised 2 tablets direct under observation on that day either before lunch or before dinner and the regimen was repeated weekly. Women in group B was instructed to take one tablet daily and supply 3 blister packets (total 30 tablets) for one month.

History was taken for compliance and side effect were noted at each visit. Complete hemogram was repeated at 1 month and 3 month after taking iron 
supplementation. Serum ferritin estimation was done at 3 month after starting iron supplementation.

\section{Results}

The present study showed maximum proportion in both groups belong to 20-24 years of age group and mean age among group A was 24.46 years whereas among group B it is 24.12 years. Hence both groups are comparable to each other (table 1). In group $B$ maximum participants did not comply because of side effects, the reason of noncompliance are significantly associated with the mode of iron supplementation $(\mathrm{p}=0.04)$ (table 2).

In our study observed that difference of haemoglobin levels at baseline and at time of final sampling is find to be statistically insignificant (p>0.05) (table 3). When the serum feeitin levels are compare between group A and group B, the difference at baseline is find to be statistically insignificant $(p>0.05)$ whereas the difference in serum ferritin levels after 3 months oral iron supplementation is find to be statistically highly significant $(\mathrm{p}<0.05)$ (table 4$)$.

In our study showed that haematological indices in group A and group B at the initiation of iron supplementation are comparable to each other. $\mathrm{P}$ value are not significant and after 3 month of iron supplementation there is no significance difference in haematological indices except in MCHC (table 5).

Table 1: Distribution of cases according to age

\begin{tabular}{|l|c|c|c|c|}
\hline \multirow{2}{*}{ Age group (yrs) } & \multicolumn{2}{|c|}{ Group A } & \multicolumn{2}{c|}{ Group B } \\
\cline { 2 - 5 } & No. & $\%$ & No. & $\%$ \\
\hline$<20$ & 18 & $18.0 \%$ & 19 & $19.0 \%$ \\
\hline $20-24$ & 40 & $40.0 \%$ & 41 & $41.0 \%$ \\
\hline $25-29$ & 41 & $41.0 \%$ & 38 & $38.0 \%$ \\
\hline $30-34$ & 1 & $1 \%$ & 2 & $2.0 \%$ \\
\hline Total & 100 & $100 \%$ & 100 & $100 \%$ \\
\hline Mean & \multicolumn{2}{|c|}{24.46} & \multicolumn{2}{c|}{24.12} \\
\hline
\end{tabular}

Table 2: Distribution of cases according to reasons for noncompliance to oral supplementation

\begin{tabular}{|c|c|c|c|c|c|}
\hline \multirow{2}{*}{ Reason for compliance } & \multicolumn{2}{|c|}{ Group A } & \multicolumn{2}{|c|}{ Group B } & \multirow[t]{5}{*}{$\mathrm{P}$ value $=0.04$} \\
\hline & No. & $\%$ & No. & $\%$ & \\
\hline Side effect & 4 & $57.14 \%$ & 17 & $60.71 \%$ & \\
\hline Refused blood sampling & 0 & $0 \%$ & 6 & $21.42 \%$ & \\
\hline Ignorance and casual attitude & 3 & $42.86 \%$ & 5 & $17.85 \%$ & \\
\hline
\end{tabular}

Table 3: Comparison of haemoglobin levels among cases at baseline and after 3 mponths.

\begin{tabular}{|l|l|l|l|}
\hline Hb levels (g/dl) & Group A & Group B & P Value \\
\hline Baseline & $10.07 \pm 1.14$ & $10.08 \pm 1.42$ & 0.294 \\
\hline After 3 months & $10.57 \pm 1.32$ & $10.24 \pm 1.50$ & 0.726 \\
\hline
\end{tabular}

Table 4: Comparison of S-Ferritin levels among cases at baseline and after 3 mponths.

\begin{tabular}{|l|l|l|l|}
\hline S-ferritin levels (ng/ml) & Group A & Group B & P Value \\
\hline Baseline & $9.55 \pm 7.75$ & $9.28 \pm 7.16$ & 0.591 \\
\hline After 3 months & $15.38 \pm 6.81$ & $11.05 \pm 4.39$ & 0.0001 \\
\hline
\end{tabular}

Table 5: Comparison of haematological indices levels among cases at baseline.

\begin{tabular}{|l|c|c|c|c|c|c|}
\hline \multirow{2}{*}{$\begin{array}{l}\text { Hematological } \\
\text { Indices }\end{array}$} & \multicolumn{2}{|c|}{ Group A } & \multicolumn{2}{c|}{ Group B } & \multicolumn{2}{c|}{ P Value } \\
\cline { 2 - 7 } & Baseline & After 3 month & Baseline & After 3 month & Baseline & After 3 month \\
\hline HCT $(\%)$ & $33.36 \pm 4.19$ & $35.22 \pm 4.86$ & $35.26 \pm 4.30$ & $35.28 \pm 4.61$ & 0.214 & 0.521 \\
\hline MCV (fl) & $85.06 \pm 10.86$ & $87.54 \pm 10.86$ & $85.74 \pm 8.86$ & $86.71 \pm 8.57$ & 0.421 & 0.598 \\
\hline MCH (pg) & $27.13 \pm 3.74$ & $28.86 \pm 5.61$ & $26.67 \pm 3.84$ & $27.76 \pm 4.09$ & 0.412 & 0.189 \\
\hline MCHC $(\mathrm{gm} / \mathrm{dl})$ & $30.73 \pm 3.08$ & $33.98 \pm 3.08$ & $30.04 \pm 3.13$ & $30.65 \pm 3.71$ & 0.67 & 0.004 \\
\hline
\end{tabular}




\section{Discussion}

Iron deficiency is the most prevalent single nutritional deficiency, nearly $50 \%$ of women with iron deficiency anaemia. Iron-folic acid (IFA) supplementation given daily from early pregnancy has long been the recommended standard approach to prevent and treat anaemia. Though efficacious, daily IFA programs have limited success in reducing anaemia in developing countries because of many reasons.

In our study showed that the range of age of study participants (20-35 years) with a mean of 24.46 years in group A and 24.12 years in group B. The two groups were comparable with respect to the distribution of the age of women. This study group is comparable with a study conducted by Mumtaz et $\mathrm{al}^{8}$ where mean age of weekly group was 24.4 years and in study by Shankar $\mathrm{H}$ et $\mathrm{al}^{9}$ age group was 17-35 years.

The present study observed that $93.45 \%$ group A patients and $78.12 \%$ group B patients complied to iron supplementation. The difference between compliance of daily and weekly supplementation was found to be statistically highly significant $\left(\mathrm{p}=0.0001\right.$ ). In the study by Ridwan et $\mathrm{al}^{10} 63 \%$ of weekly and $48 \%$ in daily groups had compliance. Our study had much better compliance in group A reason being supervised oral iron supplementation and also in group B may be because of better antenatal care. In group $A$ there is 7 patients show noncompliance due to side effect, ignorance and casual attitude whereas in group B 28 patients shows noncompliance due to side effect, refusal for blood sampling, ignorance and casual attitude. $P$ value is significant $(p=0.04)$. The main problem of routine iron supplementation is a high incidence of undesirable side effects such as epigastric pain, nausea, vomiting, constipation and diarrhoea leading to poor compliance. According to Galloway and Mc Guire ${ }^{11}$, because of low GI side effects supervised weekly iron supplementation has better compliance than daily supplementation. Goshtasebi et $\mathrm{al}^{12}$ concluded that frequency of nausea, vomiting and constipation were significantly lower in the twice weekly group. Godara $\mathrm{S}$ et al ${ }^{13}$ observed in their study that compliance among pregnant women, regarding iron supplementation, was observed by $80.47 \%$ women, noncompliance was observed by $14.42 \%$. The reasons for noncompliance were side effects $29.03 \%$. Sipra B et al ${ }^{14}$ observed that compliance was better and side effects were less in weekly iron as compared to daily iron therapy $(11.36 \%$ versus $39.9 \%$ ).

In our study observed that difference of haemoglobin levels at baseline and at time of final sampling is find to be statistically insignificant ( $p>0.05)$. The haemoglobin levels is comparable to previous studies. ${ }^{9,12,14}$ When the serum feeitin levels are compare between group A and group B, the difference at baseline is find to be statistically insignificant $(p>0.05)$ whereas the difference in serum ferritin levels after 3 months oral iron supplementation is find to be statistically highly significant $(p<0.05)$. Increase in serum ferritin is a reflection of increase of increase in storage iron. Serum ferritin level change in our study are comparable to similar studies previously conducted. $^{10}$

In our study showed that haematological indices in group A and group B at the initiation of iron supplementation are comparable to each other. $\mathrm{P}$ value was not significant. Our study groups are comparable to the other studies. ${ }^{15,16}$ After 3 month of iron supplementation there is no significance difference in haematological indices except in MCHC. Results of changes in haematological indices in our study are comparable to previous studies. ${ }^{15}$

\section{Conclusion}

Our study concluded that weekly supervised iron therapy is cheaper, easy and more compliant \& also has slightly better results than unsupervised daily iron therapy for prophylaxis of anemia. Our study is very small, large field based and multicentric studies are required to substantiate the iron supplementation efficacy of supervised weekly iron supplementation as public health strategy. 


\section{References}

1. WHO/UNICEF. Indicators and strategies fir iron deficiency and anemia programmes. World Health Organization, Geneva. 1995.

2. ICMR Evaluation of National Nutritional Anaemia Prophylaxis Programme. An ICMR Task Study. ICMR New Delhi 1989.

3. Bhatt RV. Maternal Mortality in India. FOGSI, WHO study?. J Obstet Gynec of Ind 1997;47:201-14.

4. Indian Council of Medical Research. ICMR, Task Force Study. New Delhi: Indian Council of Medical Research, 1989.

5. Solomons NW, Pineda O, Viteri FE, Sandstead HH. Studies on the bioavailability of zinc in humans: mechanism of the intestinal interaction of non-heme iron and zinc. J Nutr 1986;116: 927-935.

6. O' Neil-Cutting MA, Crosby WH. Blocking of iron absorption by a preliminary oral dose of iron. Arch Intern Med 1987;147: 489-91.

7. Book: Encyclopedia of Human Nutrition: Benzamin C., Lindsay A., Andrew P. Elsevier Academic Press. 2005.2 $2^{\text {nd }}$ Ed.:225.

8. Mumtaz Z, Sahab S, Butt N et al. Daily iron supplementation is more effective than twice weekly iron supplementation in pregnant women in Pakistan in a randomized double blind clinical trial. The Journal of Nutrition, July 2007:2697-2702.

9. Shankar H, Kumar N, Sandhir R et al. Weekly iron folic acid supplementation plays differential role in maintaining iron marker level in non anemic and anemic primigravida: a randomized controlled study. Saudi Journal of Biological Sciences, 2015:1-20.
10. Ridwan E, Schultink W, Dillon D, Gross R. Effects of weekly iron supplementation on pregnant Indonesian women are similar to those of daily supplementation. Am J Clin Nutr 1996;63:884-890.

11. Galloway R, Mc Guire J. Determinants of compliance with iron supplementation: supplies, side effects of psychology? Soc Sci Med 1994;39:381-390.

12. Goshtasebi A, Alizadeh M. Impact of twice weekly versus daily iron supplementation during pregnancy on maternal and fetal haematological indices: A randomized control trial. East Mediterr Health J. June 2012;18(6):561-6.

13. Godara $\mathrm{S}$ et al. To study compliance of antenatal women in relation to iron supplementation in routine antenatal clinic at tertiary health care centre. Journal of Drug Delivery and Therapeutics;2013: 3(3): 71-75.

14. Sipra B et al. Effect of weekly iron supplementation on iron indices in pregnant women. Int $\mathrm{J}$ Med Res Health Sci. 2015;4(4):857-860.

15. Khalid $\mathrm{S}$ et al. Effectiveness of weekly iron supplementation in anemia in pregnancy. Pakistan Journal of Pharmacology. Jan 2011;28 (1): 9-16.

16. Farahnaz $\mathrm{S}$ et al. efficacy of daily versus intermittent administration of iron supplementation in anemia or blood indices during pregnancy. Caspian J Intern Med.2013;4(1):569-573. 